This item was submitted to Loughborough's Research Repository by the author.

Items in Figshare are protected by copyright, with all rights reserved, unless otherwise indicated.

\title{
Crank length alters kinematics and kinetics, yet not the economy of recumbent handcyclists at constant handgrip speeds
}

\section{PLEASE CITE THE PUBLISHED VERSION}

https://doi.org/10.1111/sms.13859

\section{PUBLISHER}

Wiley

VERSION

AM (Accepted Manuscript)

\section{PUBLISHER STATEMENT}

This is the peer reviewed version of the following article: MASON, B.S. ... et al, 2021. Crank length alters kinematics and kinetics, yet not the economy of recumbent handcyclists at constant handgrip speeds. Scandinavian Journal of Medicine and Science in Sports, 31 (2), pp.388-397, which has been published in final form at https://doi.org/10.1111/sms.13859. This article may be used for non-commercial purposes in accordance with Wiley Terms and Conditions for Use of Self-Archived Versions.

\section{LICENCE}

CC BY-NC-ND 4.0

\section{REPOSITORY RECORD}

Mason, Barry, Ben Stone, Martin Warner, and Vicky Goosey-Tolfrey. 2020. "Crank Length Alters Kinematics and Kinetics, yet Not the Economy of Recumbent Handcyclists at Constant Handgrip Speeds". Loughborough University. https://hdl.handle.net/2134/13072022.v1. 
Crank length alters kinematics and kinetics, yet not the economy of recumbent handcyclists at constant handgrip speeds

\section{Barry S. Mason, ${ }^{1}$ Benjamin Stone, ${ }^{1}$ Martin B. Warner, ${ }^{2,3}$ Victoria L. Goosey-Tolfrey ${ }^{1}$}

${ }^{1}$ Peter Harrison Centre for Disability Sport, School for Sport, Exercise \& Health Sciences, NCSEM, Loughborough University, Loughborough, UK.

${ }^{2}$ School of Health Sciences, University of Southampton, UK.

${ }^{3}$ Arthritis Research UK Centre for Sport, Exercise and Osteoarthritis.

\section{Corresponding author:}

Dr Barry Mason, Peter Harrison Centre for Disability Sport, School for Sport, Exercise \& Health Sciences, NCSEM, Loughborough University, Loughborough, UK.

\section{Email: $\underline{\text { b.mason@lboro.ac.uk }}$}

\section{Acknowledgements}

The authors would like to thank the Engineering and Physical Sciences Research Council for funding this research and the English Institute of Sport and British cycling for their support. Thanks are also extended to all athletes who participated. No conflicts of interest are reported by any of the authors

1 Footnote

Mason and Stone should be considered joint first authors 
Handcycling performance is dependent on the physiological economy of the athlete, however handbike configuration and the biomechanical interaction between the two is also vital. The purpose of this study was to examine the effect of crank length manipulations on physiological and biomechanical aspects of recumbent handcycling performance in highly trained recumbent handcyclists at a constant linear handgrip speed and sport-specific intensity. Nine competitive handcyclists completed a 3-min trial in an adjustable recumbent handbike in four crank length settings $(150,160,170 \& 180 \mathrm{~mm})$ at $70 \%$ peak power output. Handgrip speed was controlled $\left(1.6 \mathrm{~m} \cdot \mathrm{s}^{-1}\right)$ across trials with cadences ranging from 102 to $85 \mathrm{rpm}$. Physiological economy, heart rate and ratings of perceived exertion were monitored in all trials. Handcycling kinetics were quantified using an SRM (Schoberer Rad Messtechnik) power meter and upper limb kinematics were determined using a 10-camera VICON motion capture system. Physiological responses were not significantly affected by crank length. However, greater torque was generated $(p<0.0005)$ and peak torque occurred earlier during the push and pull phase $(p \leq$ 0.001) in longer cranks. Statistical parametric mapping revealed that the timing and orientation of shoulder flexion, shoulder abduction and elbow extension was significantly altered in different crank lengths. Despite the biomechanical adaptations, these findings suggest that at constant handgrip speeds (and varying cadence) highly trained handcyclists may select crank lengths between $150-180 \mathrm{~mm}$ without affecting their physiological performance. Until further research, factors such as anthropometrics, comfort and self-selected cadence should be used to facilitate crank length selection in recumbent handcyclists.

\section{Keywords:}




\section{Introduction}

Recumbent handcycling is a Paralympic sport for athletes with a physical lower limb impairment. Handcycling performance is determined by a triad of the athlete, handbike and the handbike-user interface. However, previous research has largely focused on the physiological characteristics of the athlete, ${ }^{1-5}$ rather than the configuration of the handbike and how athletes interact with their equipment. ${ }^{6}$ Although there are numerous components to a handbike, the length of the crank arms was recently identified by handcycling experts as an area of configuration that could have a substantial bearing on performance. ${ }^{6}$ Crank arms connect the handgrips, where force is applied by the user, to the crank axis which drives the chain and the handbike forward. ${ }^{7}$ Crank lengths typically range between $160-175 \mathrm{~mm}$ in handbikes, ${ }^{8}$ with elite handcyclists often selecting between $170-175 \mathrm{~mm} .{ }^{9}$ These crank lengths mimic those observed in leg-powered cycling. ${ }^{10}$ Since the arm is approximately $30 \%$ shorter than the leg, ${ }^{11}$ it seems unlikely that settings taken from leg-powered cycling would also be optimal for handcycling. However, the effect of crank length on handcycling performance has received limited empirical research. ${ }^{12,-14}$

Of the limited previous research, a higher power output was observed in able-bodied participants during maximal effort sprinting in longer $(\sim 190 \mathrm{~mm})$ compared to shorter cranks $(\sim 139 \& \sim 164 \mathrm{~mm}) .{ }^{13}$ Whereas wheelchair users were more mechanically efficient in shorter cranks $(180 \mathrm{~mm})$ than longer cranks $(220 \mathrm{~mm})$ during submaximal handcycling $(90 \mathrm{~W})$ at fixed cadences. ${ }^{12}$ Finally, no meaningful changes in muscular activity were noted between $160 \mathrm{~mm}$ to $175 \mathrm{~mm}$ crank lengths in a single sample case study with a highly trained handcyclist, where multiple other adjustments to handbike configuration were made concurrently. ${ }^{14}$ Unfortunately, the application of these previous findings to highly trained recumbent handcyclists are limited by several factors. Firstly, the ergometer-based handbike ${ }^{13}$ and touring handbike ${ }^{12}$ used differ distinctly to the recumbent handbikes used by elite handcyclists. 
Secondly, the limited use of handcyclists as participants in addition to the non-sport specific range of crank lengths investigated further limits the application of these findings. ${ }^{12,13}$ From a methodological perspective, the fixed cadences adopted by Goosey-Tolfrey et al. ${ }^{12}$ could confound performance when investigating crank length. At fixed cadences (angular handgrip speeds), participants must move the handgrips at a higher linear speed in a longer crank to match the cadence of a shorter crank and likely accounts for the physiological differences observed with respect to crank length. ${ }^{12}$ Finally, performance in different crank length settings have only been described according to power output, physiological cost or muscle activation patterns. No previous studies have considered the kinetic or kinematic implications of crank length adjustments.

Differences in upper limb kinematics such as greater thorax flexion and shoulder extension have recently been associated with performance during recumbent handcycling. ${ }^{9}$ Further changes to kinematics have also been observed when manipulating the horizontal crank position of trained handcyclists. ${ }^{15}$ Therefore, motion analysis of upper limb kinematics could provide further insight into the optimisation of handbike, and crank length configuration. Furthermore, recent studies have frequently instrumented recumbent handbikes with Schoberer Rad Messtechnik (SRM) power meters to quantify cycle kinetics during handcycling. ${ }^{16,17}$ Whilst this research has largely explored able-bodied participants, the technology offers valuable information to further understand the effects of crank length manipulations. Although previous research has included a combination of kinematic and kinetic measures to examine the effects of different handbike configurations, ${ }^{18-21}$ no study has combined all these measures to investigate trained handcyclists, cycling at sport-specific intensities in a recumbent handbike. Subsequently the aim of the current study was to explore the impact of crank length on physiological and biomechanical aspects of recumbent handcycling at fixed linear handgrip speeds and sport-specific intensities in highly trained handcyclists. 
$\underline{\text { Participants }}$

Nine handcyclists ( 8 male; 1 female; age: $33.2 \pm 8.6$ yrs; body mass: $68.5 \pm 11.6 \mathrm{~kg}$; arm length: $67.3 \pm 2.5 \mathrm{~cm}$; classification: $4 \mathrm{H} 3$ and $5 \mathrm{H} 4$; injury description: 4 spinal cord injury (SCI) complete (T4 - T11), 1 SCI incomplete (T8), 2 lower limb amputees, 2 cerebral palsy) participated in the study. None of the participants had an upper limb impairment and all competed at national or international level in handcycling or paratriathlon (handcycling experience: $4 \pm 2$ yrs; training load: $4 \pm 2$ sessions totalling $9 \pm 4 \mathrm{~h} \cdot \mathrm{wk}^{-1}$ with a weekly selfreported distance of $\left.153 \pm 76 \mathrm{~km} \cdot \mathrm{wk}^{-1}\right)$. The local ethics advisory committee approved the study. Prior to participation, all participants provided their written, informed consent.

\section{Experimental Design}

110 Participants completed a maximal exercise test followed by four crank length experimental trials $(150,160,170 \& 180 \mathrm{~mm})$ on a power controlled handcycling ergometer (Cyclus II, RBM electronic-automation $\mathrm{GmbH}$, Leipzig, Germany) fixed in the highest gear ratio (50/10), on the same day. The maximal exercise test was performed in participants own customised recumbent handbikes, with their self-selected crank lengths (range: 165 to $175 \mathrm{~mm}$ ) to determine their peak power output (POPeak). Crank length trials were then performed in a bespoke adjustable recumbent handbike (Schmicking Reha Technik GmbH, Holzwickede, Germany) at 70\% POPeak to replicate handcycling time trial intensity. ${ }^{5}$ 
Following a 10-minute warm-up at a self-selected power and cadence, participants performed 4-minute blocks of submaximal handcycling starting at $20 \mathrm{~W}$ (15 W for females), increasing by $20 \mathrm{~W}$ (15 W for females) every 4 minutes based on a previous protocol. ${ }^{9}$ Cadence was still selected, although upper limits existed during some of the early stages. At the end of each 4minute block, a capillary blood sample was taken from the ear lobe and analysed using a Biosen C-line monitor (EKF Diagnostics, Barleben, Germany) to measure blood lactate (BLa) concentration. Submaximal tests were terminated when BLa exceeded $4 \mathrm{mmol} \cdot \mathrm{L}^{-1}$. Throughout testing, breath-by-breath expired air was collected and analysed (Cortex Metalyzer 3B, Cortex, Leipzig, Germany), to calculate peak oxygen uptake $\left(\dot{\mathrm{VO}}_{2}\right)$, determined as the highest value over a $15 \mathrm{~s}$ period. On completion of the submaximal test, participants aerobic threshold was calculated via the log-log transformation method. ${ }^{9}$ Following 30 minutes rest, a maximal incremental test to exhaustion commenced at a power output equivalent to their aerobic threshold for two minutes. Power increased at a rate of $20 \mathrm{~W} \cdot \mathrm{min}^{-1}$ for males $(5 \mathrm{~W}$ every $15 \mathrm{~s})$ and $15 \mathrm{~W} \cdot \mathrm{min}^{-1}$ for females ( $5 \mathrm{~W}$ every $20 \mathrm{~s}$ ), until volitional exhaustion, defined as a failure to maintain a cadence $\geq 50 \mathrm{rpm}$ and an overall rating of perceived exertion (RPE) between 19$20 .^{9}$

ii) Crank Length Experimental Trials

After two hours rest the adjustable handbike was configured to replicate participants recumbent handbike, using anthropometric, handbike configuration and handbike-user interface measurements. ${ }^{9}$ To achieve a standardised crank position at each crank length, crank height (2 cm clearance between handgrip and abdomen) and crank fore-aft position (97\% arm-length) were adjusted based on previous findings. ${ }^{14}$ Crank width $(33 \mathrm{~cm})$ and handgrip angle $\left(15^{\circ}\right)$ was also constant. 

crank lengths, handgrip speed was controlled $\left(1.6 \mathrm{~m} \cdot \mathrm{s}^{-1}\right)$. This led to fixed cadences of 102,96 , 90 and $85 \mathrm{rpm}$ at 150,160, 170 and $180 \mathrm{~mm}$ crank lengths respectively. 3-minute trials were

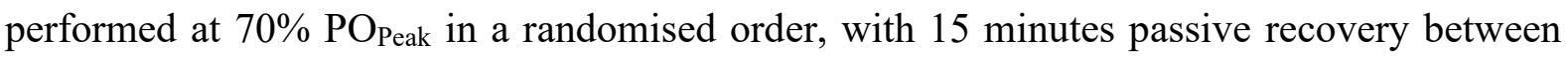
each crank length setting.

Measures

Physiology

During the last minute of each crank length trial $\mathrm{V}_{2}$ was averaged and used to quantify handcycling economy, defined as $\dot{\mathrm{V}} \mathrm{O}_{2}$ relative to power $\left(\mathrm{mL} \cdot \mathrm{min}^{-1} \cdot \mathrm{W}^{-1}\right)$ as documented previously. ${ }^{9}$ Heart rate (HR) was collected continuously at 1 -s intervals and was averaged over the final minute (Polar RS400, Polar, Kempele, Finland). At the end of each trial participants reported their local $(\mathrm{RPE}-\mathrm{L})$, central $(\mathrm{RPE}-\mathrm{C})$ and overall $(\mathrm{RPE}-\mathrm{O})$ ratings of perceived exertion using Borg's 6-20 scale. ${ }^{22}$

Kinetics

The adjustable handbike was equipped with an SRM Science Power meter and SRM Torque Analysis system (Jülich, Germany), which enabled cycle torque to be measured at $200 \mathrm{~Hz}$. Between each trial, the SRM was calibrated according to the manufacturer's instructions. Cycle torque was collected throughout the last minute of each trial and averaged across the recorded cycles. Based on previous handcycling literature, ${ }^{23}$ peak torque and the angle at which peak torque occurred during both the push and pull phase were determined for each crank length. 
Upper body kinematics were captured using a 10-camera motion capture system (Vicon T40S;

Vicon Motion Systems, Oxford, UK), sampling at $200 \mathrm{~Hz}$. Based on a previous study, ${ }^{9}$ retroreflective markers were attached to anatomical locations on the thorax, upper arm, forearm and hand. Acromion marker clusters were attached bilaterally to the acromions to determine scapular kinematics, according to previous guidelines. ${ }^{24,25}$ Two further markers were attached bilaterally to the crank arms of the handbike. With participants seated in the anatomical position, a series of static trials were captured with the tip of a calibration wand used to determine the anatomical landmarks from marker clusters. ${ }^{9,25}$ A 10 s shoulder circumduction trial was then captured to functionally determine the glenohumeral joint centre. ${ }^{26}$ For the complete and consecutive cycles in each crank length configuration.

The Optimal Common Shape Technique was used to minimise soft-tissue artefact within the kinematic data. ${ }^{27}$ The Symmetrical Centre of Rotation Estimation technique was used to calculate the glenohumeral joint centres from the circumduction trials. ${ }^{28}$ The global coordinate system was defined such that the Y-axis pointed anteriorly, the $\mathrm{X}$-axis aligned with the rotation axis of the crank, and the Z-axis pointed vertically following the right-hand rule. Anatomical local coordinate systems were then constructed and rotation sequences for the thorax, clavicle, scapula, humerus, forearm, and hand segments followed International Society of Biomechanics' recommendations. ${ }^{29}$ Three-dimensional bilateral upper body kinematics were analysed for the thorax, clavicle, scapular, shoulder, elbow, and wrist over 10 cycles. A cycle was defined as one rotation of the crank, starting with the cranks in a vertical position pointing upwards $\left(0^{\circ}\right.$ or $\left.0 \%\right)$. Crank angle was determined using Euler angles (ZXY sequence) and upper body kinematics were normalized to cycle duration $(0 \%-100 \%)$ and then averaged 
across the 10 cycles. ${ }^{9}$ Since no kinematic differences between left and right sides were identified during previous handcycling ergometry, ${ }^{9}$ only data from the right side was presented.

\section{$\underline{\text { Statistical Analysis }}$}

Statistical analyses were conducted using the Statistical Package for Social Sciences (SPSS version 24, IBM Statistics, Chicago, IL). All data were checked for normality using ShapiroWilk tests. Repeated measures analysis of variance was conducted on all physiological, kinetic and joint range of movement (RoM) kinematic data when normality was assumed. When assumptions of normality had been violated, the non-parametric Friedman test was performed. Statistical significance was accepted as $\mathrm{p}<0.05$. Pairwise comparisons with a Bonferroni correction were conducted as a post-hoc test when a significant main effect had been identified.

Statistical parametric mapping (SPM) was used to further explore upper body joint kinematics using a repeated measures SPM ANOVA. ${ }^{30}$ Where significant differences were established, SPM t-tests were conducted as a post-hoc measure to identify the time points throughout the kinematic waveform where a significant difference existed. All SPM analyses were conducted in Matlab (R2016a, 8.3.0.532, The Mathworks Inc., Natick, MA) using the open-source spm1d.code (v.M0.1, www.spm1d.org).

\section{Results}

Participants achieved a POPeak of $232 \pm 44 \mathrm{~W}$, subsequently, crank length experimental trials were performed at $163 \pm 33 \mathrm{~W}$ to reflect $70 \%$ POPeak. Results revealed that crank length had no significant effect on any physiological measure (Table 1).

***TABLE 1 HERE*** 

increased significantly with increased crank length between all settings except between 160 $\mathrm{mm}$ and $170 \mathrm{~mm}(p=0.107)$ during the push phase, and $150 \mathrm{~mm}$ and $160 \mathrm{~mm}(p=0.080)$ during the pull phase (Table 2). Crank length also significantly affected the angle at which peak torque occurred during the cycle $(p \leq 0.001)$. Peak torque occurred earlier into the push phase in a longer crank and occurred closer to top dead centre as crank length reduced, although the difference was only statistically significant between 150 and $180 \mathrm{~mm}(p=0.034)$. Peak torque also occurred earlier during the pull phase in longer cranks and later as crank length decreased. Differences were statistically significant $(p \leq 0.017)$ between all crank lengths during the pull phase (Table 2).

Crank length had a significant effect on numerous kinematic parameters during handcycling. Joint RoM significantly increased from the shortest $(150 \mathrm{~mm})$ to the longest (180 $\mathrm{mm}$ ) cranks for many joint actions (Table 3). SPM ANOVA indicated that crank length also significantly affected the internal / external rotation at the scapular and shoulder, flexion / extension at the shoulder, elbow and wrist and adduction / abduction at the shoulder. (Table 4). However, significant post-hoc differences were only revealed for shoulder flexion / extension, abduction / adduction and elbow flexion / extension. Figure 2 illustrates these differences between the two extreme crank length settings (150 vs. $180 \mathrm{~mm})$. Shoulder flexion was significantly greater during $0-26 \%$ and $73-100 \%$ of the cycle and less flexed during $48-$ $63 \%$ of the cycle in longer crank lengths. Shoulder abduction significantly increased between $68-74 \%$ of the cycle in the longer crank lengths. Elbow extension was greater during $12-$ $18 \%$ of the cycle, with more flexion observed between $42-78 \%$ of the cycle in longer cranks (Figure 2). 


\section{Discussion}

The current study was the first to provide a comprehensive insight into the effect of crank length on the physiological, kinetic and kinematic responses of trained handcyclists, whilst exercising at sport-specific intensities in a highly standardised recumbent handbike. Competitive handcyclists typically select crank lengths between $170-175 \mathrm{~mm},{ }^{9}$ and this study has revealed that although biomechanical adaptations exist, no physiological gains (or decrements) were experienced in settings either side of this range when handgrip speed is controlled.

The lack of physiological differences contrasts the only previous study in the area, ${ }^{12}$ and is likely the result of different protocols employed and the complex relationship that exists between crank length, handgrip speed and cadence. ${ }^{31}$ Unlike the current study Goosey-Tolfrey et al. ${ }^{12}$ manipulated crank length at fixed cadences. Consequently, the reduced mechanical efficiency observed in longer $(220 \mathrm{~mm})$ compared to shorter $(180 \mathrm{~mm})$ cranks was likely due to increased muscle shortening velocity required to maintain the same cadence in a longer crank. $^{32}$ In cyclic sports such as handcycling, changing crank length concurrently affects cadence and handgrip speed and ultimately performance. ${ }^{31}$ However, under no additional constraints it was perceived that athletes would automatically adjust their cadence across different crank length settings rather than maintain a fixed cadence. Subsequently, although cadence can alter the physiological demand of handcycling, ${ }^{33,34}$ it was deemed more ecologically valid to control handgrip speed in the current study.

Under such experimental conditions, the absence of any physiological and perceptual differences between crank lengths suggest that other factors must be considered to establish optimal crank length configurations, of which aerodymanics could be one. The current study 
was conducted in laboratory settings on a handycling ergometer. However, given the high speeds handcyclists reach during training and competition, ${ }^{2,35}$ air resistance can have a bearing on performance outside of a laboratory environment. Mannion et al. ${ }^{36}$ reported that the frontal area of a Paralympic handcyclist is greatest when the cranks are positioned at top dead centre and the arms are elevated away from the torso. Therefore, in the same position it is highly likely that a reduced frontal area and subsequently reduced air resistance would be experienced in shorter crank lengths, which could make these settings physiologically advantageous during overground handcycling, if athletes adjust their cadence accordingly.

A novel feature of the current study was the inclusion of biomechanical measures, never previously explored with regards to crank length. The only previous kinetic examinations of recumbent handcycling have been with able-bodied participants, where it has been revealed that greater torque was produced during the pull phase. ${ }^{21}$ Whereas the current study identified that independent of crank length, trained handcyclists produced greater torque during the push phase, which highlights why results from able-bodied studies cannot be translated to trained handcyclists. As anticipated, greater mean torque was generated in longer crank lengths. Since handgrip speed and power output was controlled, force application was likely to be similar across crank lengths and, therefore, a longer crank would result in the greater mean torque. However, the current study revealed that the peak torque also increased during both the push and pull phases as a result of increased crank length. In addition, the change in crank length also affected the timing of peak torque during both phases. Increasing crank length from the shortest $(150 \mathrm{~mm})$ to the longest $(180 \mathrm{~mm})$ setting resulted in the peak torque being generated $\sim 11^{\circ}(3 \%)$ earlier during the push phase and $\sim 13^{\circ}(4 \%)$ earlier during the pull phase. Such changes will likely affect the length-tension relationship ${ }^{37}$ and muscle activation-deactivation dynamics ${ }^{31}$ of key muscles involved. 

altered when handcycling with different crank lengths. During the push phase, the shoulder was significantly more flexed and the elbow more extended to lift up and drive forward the longer $(180 \mathrm{~mm})$ cranks compared to the shorter $(150 \mathrm{~mm})$ cranks. The shoulder was also shown to be significantly more abducted at the onset of the push phase in the longest cranks. This kinematic change was likely associated to the standardised horizontal crank position maintained across settings. Subsequently, a longer crank will pass closer to the thorax of a handcyclist, who likely compensates by abducting the shoulders to help drive the cranks up and forward, which could again make the athlete less aerodynamic in longer cranks outside of a laboratory. Conversely, during the pull phase the shoulder was significantly more extended and the elbow more flexed to pull the longer cranks down and back towards participants. Consequently, joint RoM increased for all these motions in the longest crank setting. Whether or not these biomechanical adaptations associated with different crank lengths are positive or negative remains to be seen and future research should explore the implications for injury risk understand the impact of handbike configuration on upper limb loading and injury risk. rpm, before steadily decreasing. ${ }^{13}$ Subsequently different crank lengths could be more 
been confirmed to an extent during sprinting, whereby a crank length $\sim 190 \mathrm{~mm}$ was more effective at $108 \mathrm{rpm}$, yet a shorter crank length $\sim 139 \mathrm{~mm}$ was more effective at a higher 125 rpm. ${ }^{13}$ However, to test a range of crank lengths at different cadences and handgrip speeds would result in many conditions, trials and even visits, which may not be feasible especially when examining highly trained handcyclists. Therefore, musculoskeletal modelling and computer simulation could be a more viable, alternative method for future research in this area.

To individualise findings to athletes and potentially make the findings applicable to handcyclists outside of those currently investigated, future research could benefit from making crank length adjustments relative to the physical characteristics of the user, such as arm length. This approach was previously adopted by Kramer et al. ${ }^{13}$ who manipulated crank length from $19-26 \%$ of participants arm length, which resulted in crank length setting ranging from 126 $-208 \mathrm{~mm}$. Given the likely differences in arm length between athletes it would not have been possible to test a broad range of relative crank lengths that would cater for all in the current study, without compromising the strict standardisation protocol in a recumbent handbike. However, reporting results relative to anthropometrics could provide a different insight and is worth investigating further.

\section{Perspectives}

The current study was the first to explore the effect of crank length on the physiological and biomechanical performance of trained recumbent handcyclists under highly standardised handbike settings and at fixed handgrip speeds. The findings demonstrated that crank length manipulations alter the kinetics and kinematics of recumbent handcyclists without influencing their physiological economy. Consequently, handcyclists could select any crank length between $150-180 \mathrm{~mm}$ without inhibiting their physiological responses, which are often the key determinants of performance. ${ }^{1-5}$ Therefore, until further research, factors such as comfort, 
aerodynamics and preferred cadence could be used to inform crank length selection and is of relevance to handcyclists, coaches, practitioners and also handbike manufacturers in particular.

\section{References}

1. Janssen TWJ, Dallmeijer AJ, van der Woude LHV. Physical capacity and race performance of handcycle users. J Rehabil Res Dev 2001;38:33-40.

2. Abel T, Schneider S, Platen P, Struder HK. Performance diagnostics in handbiking during competition. Spinal Cord 2006;44:211-216.

3. de Groot S, Postma K, van Vliet L, Timmermans R, Valent L. Mountain time trial in handcycling: exercise intensity and predictors of race time in people with a spinal cord injury. Spinal Cord 2014;52:455-461.

4. Fischer G, Figueiredo P, Ardigo LP. Physiological performance determinants of a 22 km handbiking time trial. Int J Sports Physiol Perform 2015;10:965-971.

5. Stone B, Mason BS, Stephenson BT, Goosey-Tolfrey VL. Physiological responses during simulated $16 \mathrm{~km}$ recumbent handcycling time trial and determinants of performance in trained handcyclists. Eur J Appl Physiol 2020;120:1621-1628.

6. Stone B, Mason BS, Bundon A, Goosey-Tolfrey VL. Elite handcycling: a qualitative analysis of recumbent handbike configuration for optimal sports performance. Ergonomics 2019;62:449-458.

7. Zipfel E, Olson J, Puhlman J, Cooper RA. Design of a custom racing hand-cycle: review and analysis. Disabil Rehabil Assist Technol 2009;4:119-128.

8. Litzenberger S, Mally F, Sabo A. Biomechanics of elite recumbent handcycling: a case study. Sports Eng 2016;19:1-11. 
9. Stone B, Mason BS, Warner MB, Goosey-Tolfrey VL. Shoulder and thorax kinematics contribute to increased power output of competitive handcyclists. Scand J Med Sci Sports 2019;29:843-853.

10. Ferrer-Roca V, Rivero-Palomo V, Ogueta-Alday A, Rodriguez-Marroyo JA, GarciaLopez J. Acute effects of small changes in crank length on gross efficiency and pedalling technique during submaximal cycling. J Sports Sci 2017;35:1328-1335.

11. Gordon CC, Churchill T, Clauser CE, et al. 1988 Anthropometric Survey of U.S. Army Personnel: Summary Staistics: Interim Report. Natick Labs, Yellow Springs, OH. 1989.

12. Goosey-Tolfrey VL, Alfano H, Fowler N. The influence of crank length and cadence on mechanical efficiency in hand cycling. Eur J Appl Physiol 2008;102:189-194.

13. Kramer C, Hilker L, Bohm H. Influence of crank length and crank width on maximal hand cycling power and cadence. Eur J Appl Physiol 2009;106:749-757.

14. Litzenberger S, Mally F, Sabo A. Biomechanics of elite recumbent handcycling: a case study. Sports Biomech 2016;19:201-211.

15. Stone B, Mason BS, Warner MB, Goosey-Tolfrey VL. Horizontal crank position affects economy and upper limb kinematics of recumbent handcyclists. Med Sci Sports Exerc 2019;51:2265-2273.

16. Quittman OJ, Abel T, Albracht K, Meskemper J, Foitschik T, Strueder HK. Biomechanics of handcycling propulsion in a 30-min continuous load test at lactate threshold: kinetics, kinematics and muscular activity in able-bodied participants. Eur J Appl Physiol 2020;120:1403-1415.

17. Quittmann OJ, Abel T, Albracht K, Strueder HK. Biomechanics of all-out handcycling exercise: kinetics, kinematics and muscular activity of a 15 -s sprint test in able-bodied participants. Sports Biomech 2020;Epub ahead of print:7 May 2020 https://doi.org/10.1080/14763141.2020.1745266 
18. Faupin A, Gorce P, Meyer C, Thevenon A. Effects of backrest positioning and gear ratio on nondisabled subjects handcycling sprinting performance and kinematics. $\mathbf{J}$ Rehabil Res Dev 2008;45:109-116.

19. Kramer C, Schneider G, Bohm H, Klopfer-Kramer I, Senner V. Effect of different handgrip angles on work distribution during hand cycling at submaximal power levels. Ergonomics 2009;52:1276-1286.

20. Arnet U, van Drongelen S, Schlussel M, Lay V, van der Woude LHV. The effect of crank position and backrest inclination on shoulder load and mechanical efficiency during handcycling. Scand J Med Sci Sport 2014;24:386-394.

21. Vegter RJK, Mason BS, Sporrel B, van der Woude LHV, Goosey-Tolfrey VL. Crank fore-aft position alters the distribution of work over the push and pull phase during synchronous recumbent handcycling in able-bodied participants. PLoS One 2019; 14:e0220943.

22. Borg G. Borg's perceived exertion and pain scales. Human Kinetics, Champaign, IL. 1998.

23. Verellen J, Janssens L, Meyer C, Vanlandewijck Y. Development and application of a handbike ergometer to measure 3D force generation pattern during arm crank propulsion in realistic handcycling conditions. Sport Technol 2012;5:65-73.

24. Shaheen AF, Alexander CM, Bull A. Effects of attachment position and shoulder orientation during calibration on the accuracy of the acromial tracker. J Biomech 2011;44:1410-1413.

25. Warner MB, Chappell PH, Stokes MJ. Measurement of dynamic scapular kinematics using an acromion marker cluster to minimize skin movement artifact. J Vis Exp 2015;96:1-14. 
26. Monnet T, Desailly E, Begon M, Vallee C, Lacouture P. Comparison of the SCoRE and HA methods for locating in vivo the glenohumeral joint centre. J Biomech 2007;40:3487-3492.

27. Taylor WR, Ehrig RM, Duda, GN, Schell H, Seebeck P, Heller MO. On the influence of soft tissue coverage in the determination of bone kinematics using skin markers. $\mathrm{J}$ Orthop Res 2005;23:726-734.

28. Ehrig RM, Taylor WR, Duda GN, Heller MO. A survey of formal methods for determining the centre of rotation of ball joints. J Biomech 2006;39:2798-2809.

29. Wu G, van der Helm, Veeger $\mathrm{H}$, et al. ISB recommendation on definitions of joint coordinate systems of various joints for the reporting of human joint motion - part II: shoulder, elbow, wrist and hand. J Biomech 2005;38:981-992.

30. Pataky TC, Robinson MA, Vanrenterghem J. Vector field statistical analysis of kinematic and force trajectories. J Biomech 2013;46:2394-2401.

31. Martin JC, Spiriduso WW. Determinants of maximal cycling power: crank length, pedalling rate and pedal speed. Eur J Appl Physiol 2001;84:413-418.

32. Barratt PR, Martin JC, Elmer SJ, Korrf T. Effects of pedal speed and crank length on pedalling mechanics during submaximal cycling. Med Sci Sports Exerc 2016;48:705713.

33. Verellen J, Theisen D, Vanlandewijck Y. Influence of crank rate in hand cycling. Med Sci Sports Exerc 2004;36:1826-1831.

34. Kraaijenbrink C, Vegter RJK, Hensen AHR, Wagner H, van der Woude LHV. Different cadences and resistances in submaximal synchronous handcycling in able-bodied men: effects on efficiency and force application. PLoS One 2017;12:e0183502.

35. Zeller S, Abel T, Strueder HK. Monitoring training load in handcycling: a case study. J Strength Cond Res 2017;31:3094-3100. 
36. Mannion P, Toparlar Y, Clifford E, Hajdukiewicz M, Andrianne T, Blocken B. The impact of arm-crank position on the drag of a Paralympic hand-cyclist. Comput Methods Biomech Biomed Eng 2019;22:386-395. cross the elbow. J Biomech 2000;33:943-952.

439 
Table 1. Mean \pm SD physiological measures of performance in different crank lengths.

\begin{tabular}{llccccc}
\hline & & $\boldsymbol{P}$ & $\mathbf{1 5 0} \mathbf{~ m m}$ & $\mathbf{1 6 0} \mathbf{~ m m}$ & $\mathbf{1 7 0 ~} \mathbf{~ m m}$ & $\mathbf{1 8 0} \mathbf{~ m m}$ \\
\hline Economy & $\left(\mathrm{mL} \cdot \mathrm{min}^{-1} \cdot \mathrm{W}^{-1}\right)$ & 0.942 & $16.5 \pm 3.0$ & $16.2 \pm 2.0$ & $16.3 \pm 2.6$ & $16.2 \pm 2.2$ \\
Heart rate & $\left(\right.$ beats $\left.\cdot \mathrm{min}^{-1}\right)$ & 0.065 & $166 \pm 12$ & $164 \pm 12$ & $161 \pm 14$ & $159 \pm 15$ \\
RPE - L & & 0.568 & $15 \pm 2$ & $14 \pm 1$ & $15 \pm 2$ & $15 \pm 1$ \\
RPE - C & 0.246 & $15 \pm 3$ & $14 \pm 2$ & $14 \pm 2$ & $14 \pm 2$ \\
RPE - O & 0.697 & $15 \pm 2$ & $14 \pm 2$ & $15 \pm 2$ & $14 \pm 2$ \\
\hline
\end{tabular}

Table 2. Mean \pm SD cycle kinetics during the push and pull phase in different crank lengths.

\begin{tabular}{|c|c|c|c|c|c|c|}
\hline & & $p$ & $150 \mathrm{~mm}$ & $160 \mathrm{~mm}$ & $170 \mathrm{~mm}$ & $180 \mathrm{~mm}$ \\
\hline \multicolumn{7}{|l|}{ Push } \\
\hline Peak Torque & $\mathrm{N} \cdot \mathrm{m}^{-1}$ & $<0.0005$ & $32.8 \pm 6.6$ & $35.2 \pm 6.4^{*}$ & $37.6 \pm 7.3^{*}$ & $41.8 \pm 8.9^{* \# \wedge}$ \\
\hline \multirow[t]{2}{*}{ Peak torque angle } & Degrees $\left({ }^{\circ}\right)$ & 0.001 & $358.2 \pm 10.2$ & $356.9 \pm 9.9$ & $352.8 \pm 13.3$ & $347.4 \pm 13.2 *$ \\
\hline & $\%$ cycle & & $99.5 \pm 2.8$ & $99.1 \pm 2.8$ & $98.0 \pm 3.7$ & $96.5 \pm 3.7$ \\
\hline \multicolumn{7}{|l|}{ Pull } \\
\hline Peak Torque & $\mathrm{N} \cdot \mathrm{m}^{-1}$ & $<0.0005$ & $28.6 \pm 5.8$ & $30.9 \pm 7.4$ & $33.6 \pm 8.4^{* \#}$ & $36.3 \pm 8.7 * \# \wedge$ \\
\hline \multirow[t]{2}{*}{ Peak torque angle } & Degrees $\left({ }^{\circ}\right)$ & $<0.0005$ & $152.3 \pm 8.1$ & $148.6 \pm 8.4^{*}$ & $144.1 \pm 8.9 * \#$ & $138.8 \pm 8.7^{* \# \wedge}$ \\
\hline & $\%$ cycle & & $42.3 \pm 2.3$ & $41.3 \pm 2.3$ & $40.0 \pm 2.5$ & $38.6 \pm 2.4$ \\
\hline
\end{tabular}

Significant difference to: $* 150 \mathrm{~mm},{ }^{\#} 160 \mathrm{~mm}, \wedge 170 \mathrm{~mm}$ 
Table 3. Mean \pm SD joint range of movements $\left(^{\circ}\right)$ of handcyclists in different crank lengths.

\begin{tabular}{|c|c|c|c|c|c|}
\hline & $p$ & 150 & 160 & 170 & 180 \\
\hline \multicolumn{6}{|l|}{ Thorax } \\
\hline Flexion/extension & 0.530 & $4.0 \pm 1.4$ & $3.7 \pm 1.3$ & $4.2 \pm 1.4$ & $4.0 \pm 1.4$ \\
\hline \multicolumn{6}{|l|}{ Clavicle } \\
\hline Protraction/retraction & 0.479 & $9.6 \pm 1.6$ & $9.9 \pm 2.1$ & $10.2 \pm 2.1$ & $10.4 \pm 1.8$ \\
\hline Elevation/depression & 0.242 & $7.0 \pm 2.3$ & $7.1 \pm 2.9$ & $7.5 \pm 2.2$ & $7.6 \pm 3.0$ \\
\hline \multicolumn{6}{|l|}{ Scapular } \\
\hline Internal/external rotation & $<0.0005$ & $17.5 \pm 4.1$ & $18.3 \pm 5.2$ & $19.3 \pm 4.5^{*}$ & $20.6 \pm 5.6^{* \#}$ \\
\hline Upward/downward rotation & 0.045 & $11.3 \pm 3.0$ & $12.0 \pm 3.2$ & $13.1 \pm 3.5$ & $12.9 \pm 3.8$ \\
\hline Anterior/posterior tilt & 0.004 & $15.2 \pm 3.2$ & $15.0 \pm 3.3$ & $16.9 \pm 5.2$ & $18.0 \pm 5.1^{*}$ \\
\hline \multicolumn{6}{|l|}{ Shoulder } \\
\hline Flexion/extension & $<0.0005$ & $54.6 \pm 4.9$ & $58.9 \pm 5.2 *$ & $62.3 \pm 4.7^{* \#}$ & $66.0 \pm 5.0^{* \# \wedge}$ \\
\hline Abduction/adduction & 0.001 & $19.8 \pm 3.8$ & $22.5 \pm 3.9 *$ & $23.1 \pm 4.4^{*}$ & $24.7 \pm 4.4^{* \wedge}$ \\
\hline Internal/external rotation & $<0.0005$ & $41.2 \pm 8.2$ & $44.0 \pm 8.7^{*}$ & $44.4 \pm 8.7^{*}$ & $47.3 \pm 8.6^{* \#}$ \\
\hline \multicolumn{6}{|l|}{ Elbow } \\
\hline Flexion/extension & $<0.0005$ & $73.6 \pm 8.3$ & $77.8 \pm 9.4^{*}$ & $81.8 \pm 10.0^{* \#}$ & $86.0 \pm 9.4^{* \# \wedge}$ \\
\hline Pronation/supination & 0.053 & $23.9 \pm 6.7$ & $24.7 \pm 7.7$ & $26.9 \pm 8.6$ & $28.0 \pm 9.4$ \\
\hline \multicolumn{6}{|l|}{ Wrist } \\
\hline Flexion/extension & 0.414 & $15.6 \pm 6.6$ & $15.3 \pm 7.2$ & $17.4 \pm 6.1$ & $16.9 \pm 5.4$ \\
\hline Radial/ulnar deviation & 0.001 & $25.8 \pm 7.4$ & $27.7 \pm 8.2$ & $29.1 \pm 7.5$ & $30.1 \pm 6.9^{*}$ \\
\hline
\end{tabular}

Significant difference to: * $150 \mathrm{~mm},{ }^{\#} 160 \mathrm{~mm}, \wedge 170 \mathrm{~mm}$ 
Table 4. Statistical Parametric Mapping ANOVA and post-hoc comparisons of handcycling kinematics in different crank lengths.

\begin{tabular}{|c|c|c|c|c|c|c|c|}
\hline & $p$ & 150 v. 160 & 150 v. 170 & 150 v. 180 & 160 v.170 & 160 v. 180 & 170 v. 180 \\
\hline \multicolumn{8}{|l|}{ Thorax } \\
\hline Flexion/extension & ns & - & - & - & - & - & - \\
\hline \multicolumn{8}{|l|}{ Clavicle } \\
\hline Protraction/retraction & ns & - & - & - & - & - & - \\
\hline Elevation/depression & ns & - & - & - & - & - & - \\
\hline \multicolumn{8}{|l|}{ Scapular } \\
\hline Internal/external rotation & 0.048 & ns & ns & ns & ns & ns & ns \\
\hline Upward/downward rotation & ns & - & - & - & - & - & - \\
\hline Anterior/posterior tilt & ns & - & - & - & - & - & - \\
\hline \multicolumn{8}{|l|}{ Shoulder } \\
\hline Flexion/extension & 0.020 & $<0.001$ & $<0.001$ & $<0.001$ & $<0.001$ & $<0.010$ & $<0.010$ \\
\hline Abduction/adduction & $<0.001$ & ns & ns & 0.005 & ns & ns & ns \\
\hline Internal/external rotation & 0.047 & ns & ns & ns & ns & ns & ns \\
\hline \multicolumn{8}{|l|}{ Elbow } \\
\hline Flexion/extension & $<0.001$ & $<0.005$ & $<0.005$ & $<0.005$ & ns & $<0.001$ & $<0.001$ \\
\hline Pronation/supination & ns & - & - & - & - & - & - \\
\hline \multicolumn{8}{|l|}{ Wrist } \\
\hline Flexion/extension & 0.047 & ns & ns & ns & ns & ns & ns \\
\hline Radial/ulnar deviation & ns & - & - & - & - & - & - \\
\hline
\end{tabular}




\section{Figure Legends}

Figure 1 - Mean torque $\left(\mathrm{N} \cdot \mathrm{m}^{-1}\right)$ trace throughout the cycle in different crank lengths

Figure 2 - Comparison of mean kinematic trajectories ( \pm SD cloud) of handcyclists in $150 \mathrm{~mm}$ (black lines) vs. $180 \mathrm{~mm}$ (green lines) crank lengths. Line represents the mean of all cycles (n $=90$ ). Grey shaded regions identify significant differences between settings. $\mathrm{P}$ values are provided for each supra-threshold cluster 
$-150-160-170-180$

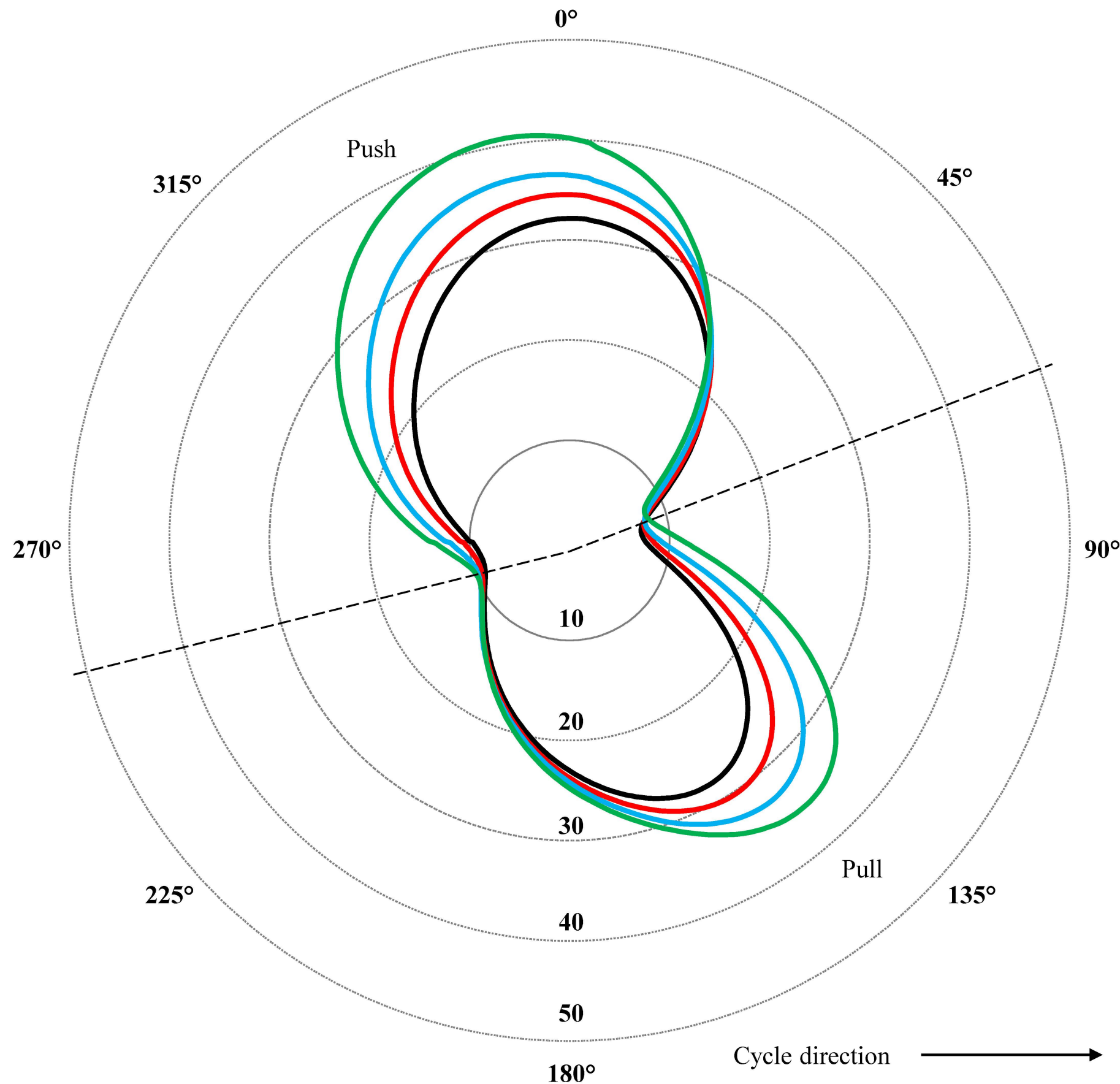


a)
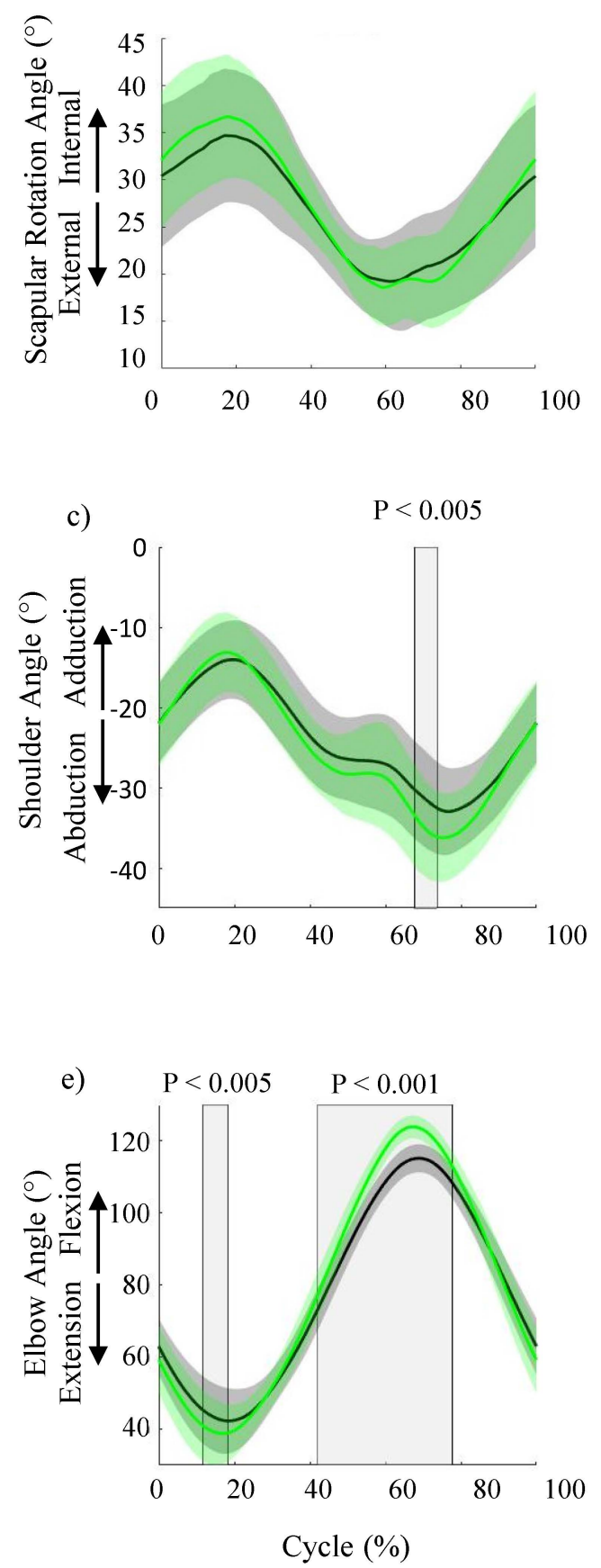

b) $\quad$ P $<0.001 \quad$ P $<0.001 \quad$ P $<0.001$

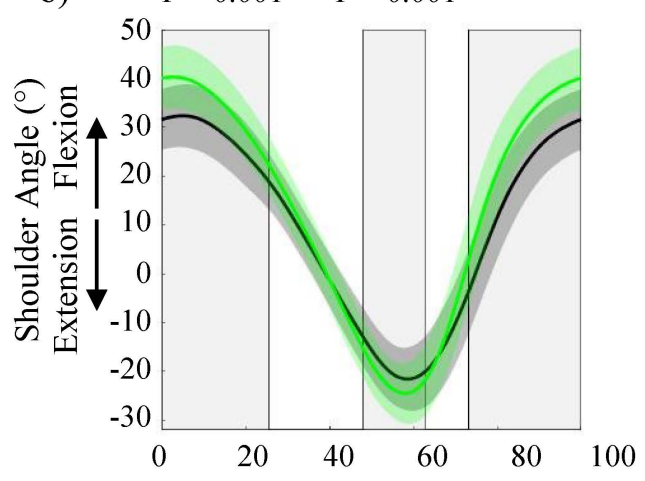

d)

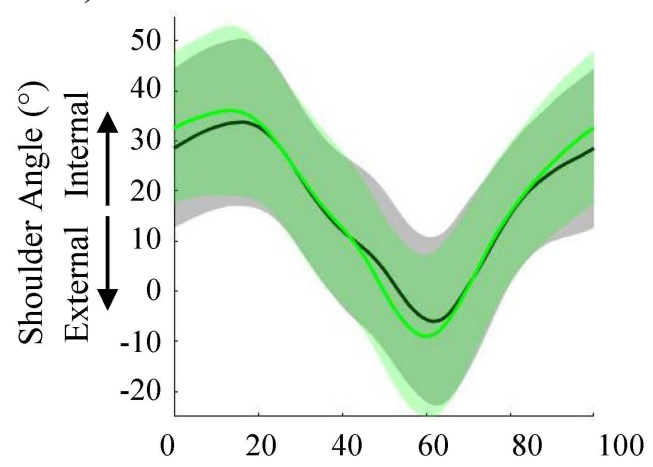

f)

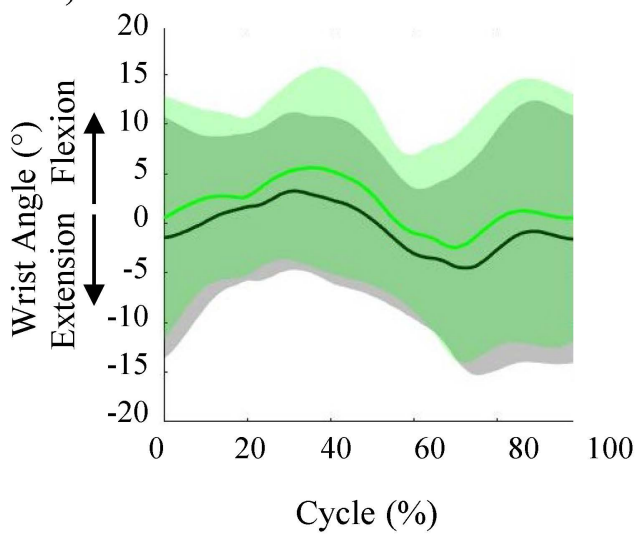

